\title{
Old Sins Throw Long Shadows - Old and Emerging Persistent Organic Pollutants in the Swiss Environment
}

\author{
Peter Schmid, Martin Kohler, Andreas C. Gerecke, Erika Gujer, Markus Zennegg, \\ and Max Wolfensberger*
}

\begin{abstract}
Temporal trends and concentrations of dioxins and polybrominated diphenyl ethers in the Swiss environment are presented.
\end{abstract}

Keywords: Brominated flame retardants (BFR) · Dioxins · Persistent organic pollutants (POP) · Polychlorinated dibenzo- $p$-dioxins (PCDD) · Polychlorinated dibenzofurans (PCDF) •

Polybrominated diphenyl ethers (PBDE)

\section{Introduction}

The list of persistent, bio-accumulative and toxic chemicals (PBT) present in the environment has been continually growing since the detrimental long-term side effects caused by the use of synthetic pesticides such as DDT and other organochlorines were discovered in the sixties [1]. In 1995, the United Nations Environment Programme (UNEP) identified twelve particularly toxic compounds (persistent organic pollutants, POP). The Stockholm Convention, signed in 2001, targets POP for reduction and eventual elimination and sets up a system for tackling additional chemicals identified as unacceptably hazardous. The twelve POP include pesticides (aldrin, dieldrin, DDT, endrin, chlordan, hexachlorobenzene, mirex, toxaphene, and heptachlor), technical chemicals (polychlorinated biphenyls, PCB), as well as polychlorinated dibenzo- $p$-dioxins and dibenzofurans (PCDD and PCDF). The substances enter the environment from various sources, i.e. via direct application (e.g. pesticides), release from applications (PCB), and from side-reactions in thermal

\footnotetext{
${ }^{*}$ Correspondence: Dr. M. Wolfensberger Laboratory of Organic Chemistry

Swiss Federal Laboratories for Materials Testing and Research (EMPA)

Überlandstrasse 129, CH-8600 Dübendorf

Tel.: +4118234132

Fax: +4118234041

E-Mail: max.wolfensberger@empa.ch

www.empa.ch
}

processes (dioxins). POP are prone to long range atmospheric transport and subsequent deposition.

EMPA contributes to the reduction of the pollution of the atmospheric boundary layer as well as of the emission of greenhouse gases through the investigation of fluxes of pollutants between the technosphere and the atmosphere within its framework program TECAT (TEChnosphereATmosphere). EMPA's Laboratory of Organic Chemistry has extensive experience in the investigation of various aspects of PBT including the substances and topics given in Table 1.

With the refinement of trace analytical methods, the focus of interest has shifted more and more from source-oriented towards target-oriented investigations. The current activities in environmental research are centered on the environmental behavior of PBT. In this article, two examples on the environmental behavior of 'old' and 'new' contaminants will be presented: Since the Seveso accident in 1976, dioxins are perceived as archetypes of environmental contaminants. Due to various reduction measures, environmental levels as well as the dioxin exposure of the population have been steadily decreasing during the last 20 years. On the other hand, the brominated flame retardants (e.g. polybrominated diphenyl ethers, hexabromocyclododecane, tetrabromobisphenol A) represent a class of emerging contaminants with world-wide increasing production rates. Some brominated flame retardants exhibit sharply increasing environmental levels, due to their

Table 1. Various aspects of PBTs including some other substances and topics

Polychlorinated dibenzo-p-dioxins and dibenzofurans (PCDD and PCDF) detection in emissions from incineration plants [2-4], formation in automotive combustion [5], monitoring in food and in feedingstuffs [6]

Polychlorinated biphenyls (PCB) from sealing materials in indoor air [7]

Emission of polycyclic aromatic hydrocarbons $(\mathrm{PAH})$ from materials for road surfaces and from railroad ties [8][9]

Toxic emissions from road traffic (volatile organic compounds [10-15], polycyclic aromatic and nitroaromatic hydrocarbons, and dioxins [16][17])

Secondary emissions from exhaust gas after-treatment [5][11][14][16]

Fate of brominated flame retardants (BFR) in the environment (NRP50: Endocrine Disruptors: Relevance to Humans, Animals and Ecosystems) [18][19] Nitrated phenolic compounds in the atmosphere [20] 
high bioaccumulation potential and persistence. At present, much remains uncertain regarding their biological implications in humans and wildlife.

\section{Temporal Trend of Atmospheric Dioxin Input in Switzerland (adapted from [21])}

The ubiquitous contamination of the environment by dioxins (polychlorinated dibenzo- $p$-dioxins and dibenzofurans, PCDD and PCDF) is primarily caused by atmospheric transport and subsequent deposition of emissions from various sources (waste incineration and other industrial thermal processes, production of chemicals, traffic). Due to their physical properties, the bulk of the dioxins is adsorbed to dust and soot particles. These particles are deposited by atmospheric deposition on soil and leafy vegetation such as grass. Grazing cows ingest contaminated grass, or hay and silage. Thereafter the dioxins, which are lipophilic and persistent, are transferred into the fat compartment including the milk fat of the lactating cow. Therefore, milk constitutes an efficient and rapid elimination pathway of these contaminants. If milk production is exclusively based on grazing, the resulting dioxin levels in cows' milk reflect the atmospheric deposition on the pasture and can be used as indicators for the actual average local dioxin exposure [22-26]. Due to the duration of the vegetation period of grass and due to the elimination half-life in the cow of approximately 40 days, cows' milk can be regarded as a biomonitor reflecting atmospheric longterm input of dioxins. Already in 1984 and 1990/1991, investigations on cows' milk in Switzerland from various locations were conducted to identify strong dioxin emittents (e.g. waste incineration and metal recycling plants) and to gain data on the human exposure of the Swiss population by dioxins from dairy products [8][9]. A follow-up investigation was initiated in 2001, aimed at establishing temporal trends of the atmospheric dioxin input in Switzerland. A further objective of the present investigation was the determination of dioxin levels in milk from non-contaminated remote areas. For this purpose, remote sample locations with distinct alpine characteristics were chosen. As in the 1984 and 1990/1991 campaigns, pooled milk samples from large industrial milk processing plants were analyzed in order to determine the average dioxin levels in consumer milk from different regions in Switzerland.

The results of the three studies carried out in 1984, 1990/1991, and 2001 are sum- marized in Table 2. Sampling locations of milk from nearby point sources and from rural and alpine locations are given in Fig. 1. The concentrations of dioxins are expressed as total toxicity equivalents (I-TEQ and WHO-TEQ, respectively), reflecting the total of levels of the relevant dioxins weighted by their respective toxicities. In 2001 , the average dioxin level in Swiss consumer milk (six samples of pooled milk from the main industrial milk processing plants in Switzerland) was only slightly above the average concentration determined in 13 milk samples from rural/alpine regions (see Fig. 1). The average level of eleven samples collected in the proximity of potential and former point sources was slightly but significantly elevated compared to milk from remote areas: These levels are well in line with the most recent national average dioxin levels in countries of the European Union, being in a range of 0.32-2.1 ng I-TEQ/kg milk fat [29]. Based on the average level in milk from industrial processors, the average intake of dairy Swiss products exploits approximately $40 \%$ of the lower end of the range of the tolerable daily intake of dioxins and dioxinlike polychlorinated biphenyls defined by WHO (1-4 pg WHO-TEQ/kg body weight) [30].

\section{Dioxin Levels in the Past}

Comparison of actual dioxin levels in cows' milk with data gathered in 1984 and 1990/1991 generally demonstrates distinct decreases, both in samples from the neighborhood of former, remediated point sources and in remote locations where dioxin input is due to long-range atmospheric transport of these contaminants. As some of these plants are still in operation,

Table 2. Average dioxin levels in cows' milk (ng l-TEQ/kg, milk fat basis) from different sites in Switzerland 1984 [27], 1990/1991 [28], and 2001 [21].

\begin{tabular}{lccc} 
& 1984 & $1990 / 1991$ & 2001 \\
\hline $\begin{array}{l}\text { Pooled milk from industrial } \\
\text { milk processing plants }\end{array}$ & & & \\
$\begin{array}{l}\text { Range } \\
\text { Average }\end{array}$ & 1.9 & $1.0-1.8$ & $0.32-0.85$ \\
\hline $\begin{array}{l}\text { Milk from locations with } \\
\text { nearby point sources }\end{array}$ & 1.9 & $1.3 \pm 0.23$ & $0.51 \pm 0.19$ \\
$\begin{array}{l}\text { Range } \\
\text { Average }\end{array}$ & $4.6-12$ & $2.0-4.4$ & \\
\hline $\begin{array}{l}\text { Milk from rural and alpine } \\
\text { locations }\end{array}$ & $8.5 \pm 3.0$ & $3.0 \pm 0.87$ & $0.28-1.1$ \\
Range & & & $0.63 \pm 0.26$ \\
Average & 1.8 & $0.7-2.2$ & \\
\hline
\end{tabular}

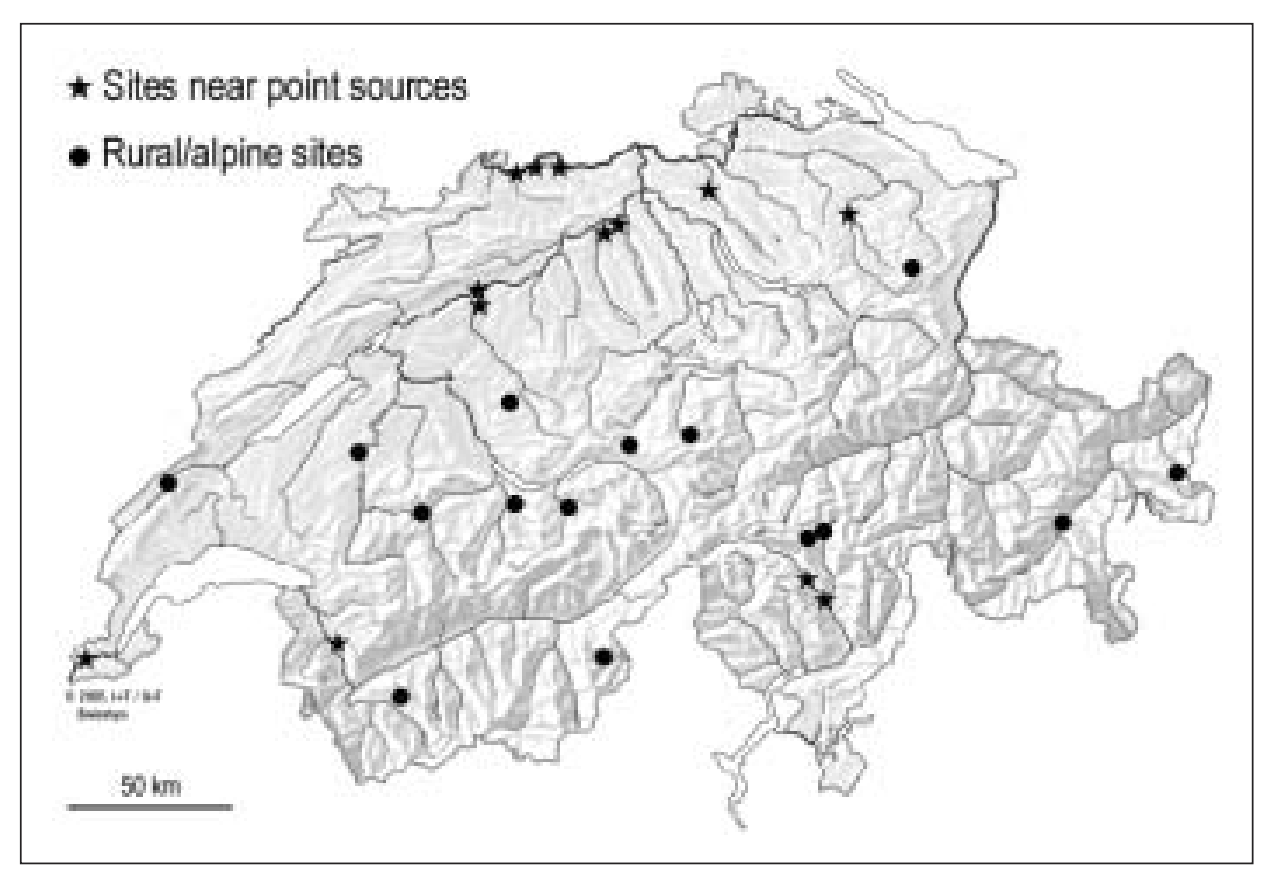

Fig. 1. Sites of origin of cows' milk samples taken in 2001. 
the observed decrease can be attributed to the efficiency of reduction measures taken in the meantime. According to the Swiss Agency for the Environment, Forests and Landscape, the total annual emissions of dioxin from all Swiss waste incineration plants decreased from $440 \mathrm{~g}$ I-TEQ in 1985 to $72 \mathrm{~g}$ I-TEQ in 2000, and for 2005 a total annual emission of $66 \mathrm{~g}$ I-TEQ is predicted [31]. Similarly, a decrease of $c a$. $80 \%$ is estimated for the total annual European dioxin emissions between 1985 and 2005 [32]. Fig. 2 shows the average dioxin levels in milk samples from industrial milk processing plants for the three sampling periods, indicating a steady decrease since 1984 Similar downward trends have been observed in other European countries [33-35]. Still, the profile in Fig. 2 gives rise to the question of the culmination of dioxin levels in cows' milk. Unfortunately, no data on dioxin content is available for Swiss milk before 1984. However, some information on historical atmospheric deposition can be gained from investigations on aquatic sediment cores which suggest a dramatic increase of dioxin deposition after $c a .1950$ in Europe and North America [35]. These observations are in line with estimates of the total annual dioxin emissions in Switzerland between 1950 and 2010 (Fig. 2 , solid line), localizing the maximum emissions around 1980 [31].

\section{Polybrominated Diphenyl Ethers in Whitefish From Swiss Lakes and Farmed Rainbow Trout (adapted from [36])}

Polybrominated diphenyl ethers (PBDE) are a class of flame retardants for which ubiquitous occurrence and increasing levels in the environment have been observed [37]. PBDE are released into the environment mainly from plastic materials and textiles where they are used as flame retardants. In plastics treated with flame retardants, they account for 5-30\% of the total weight [38]. Brominated flame retardants are very successful on the global market; they have become the second largest additives used by the plastics industry [39]. The world-wide demand for brominated flame retardants in 1999 was about 204'000 metric tons, including about 67'000 metric tons of PBDE [40]. Most commercial PBDE products are mixtures of various brominated diphenyl ethers (congeners). Pentabromodiphenyl ether (PeDBE) is a mixture of tetra- to hexabromodiphenyl ethers. Octabromodiphenyl ether (OcBDE) contains hexa- to nonabromodiphenyl ethers (mainly heptabro-

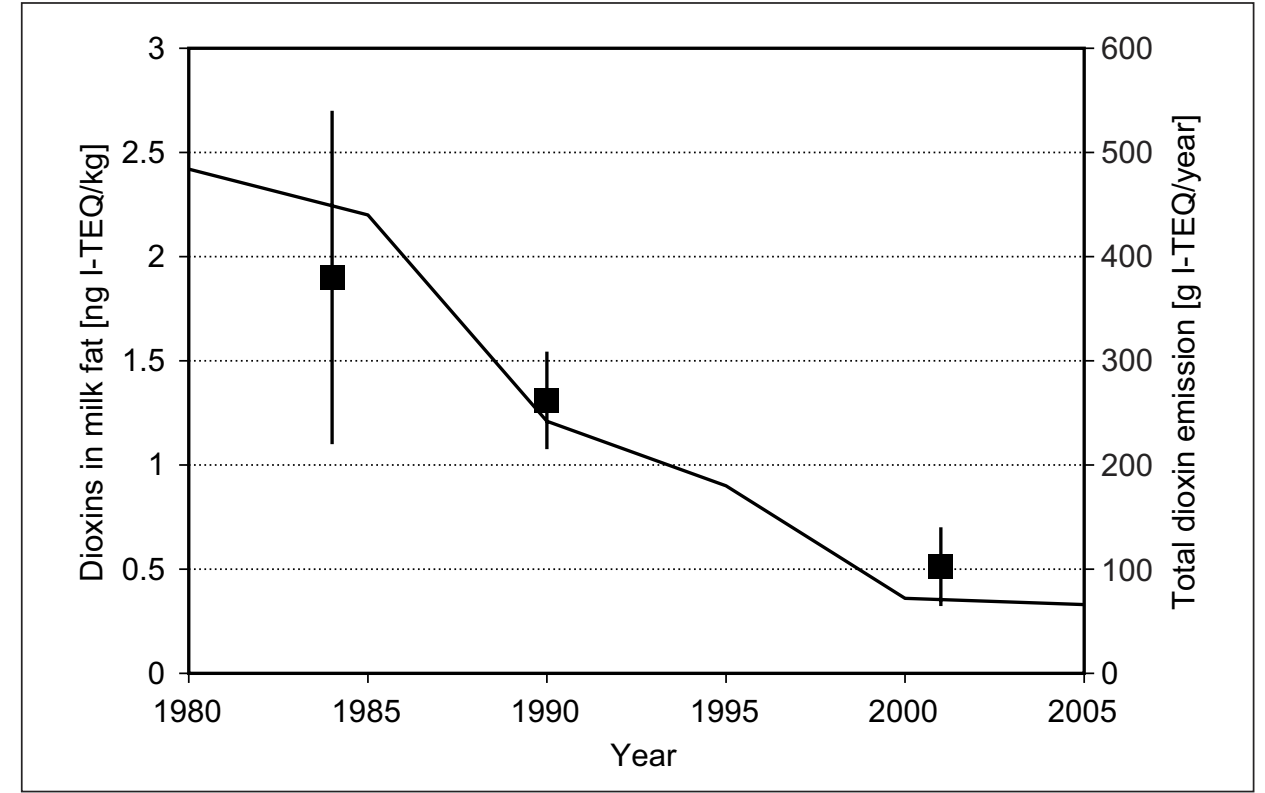

Fig. 2. Temporal trend of average dioxin levels in pooled cows' milk from Swiss industrial milk processing plants (error bars indicate levels including 100\% and 0\% of the detection limit (1984 data), or standard deviations (1990/1991 and 2001 data)). For comparison: the solid line shows the estimated total annual dioxin emissions in Switzerland [31].

modiphenyl ether), and decabromodiphenyl ether (DeBDE) consists to 97-98\% of the congener BDE-209 (decabromodiphenyl ether). Table 3 shows the most abundant PBDE congeners present in commercial products.

Although PBDE exhibit typical characteristics of POP (persistent organic pollutants), they have not yet been added to the POP list of the United Nations Environment Programme (UNEP). Similar to dioxins and PCB, brominated flame retardants have been shown to accumulate in the food chain, and they can be found in samples from all over the world [41]. Brominated flame retardants were even detected in whales living in deeper Atlantic waters [42]. A recent study from North America reports PBDE levels up to $200 \mathrm{ng} / \mathrm{g}$ based on lipid weight (lw) in human milk [43]. Ac- cording to Norén and Meironyté [44], levels of PBDE in human milk have doubled every five years between 1972 and 1999, while levels of other organochlorine compounds have decreased to various extents. Recently, endocrine disruption properties have been discovered for flame retardants such as PBDE [45] and tetrabromobisphenol A (TBBPA) [46]. Endocrine disrupting effects triggered by these and other chemicals are discussed to be responsible for various disorders and the diminution of fish populations.

PBDE were determined in pooled whitefish (Coregonus sp.) samples originating from eight Swiss lakes. Whitefish is an abundant zooplanktophagous species and a popular food fish [47]. Typical prey of whitefish are Daphnia and Bythotrephes [47], setting Coregonus sp. on a medium

Table 3. Polybrominated diphenyl ethers (PBDE). Typical congeners include BDE-28, BDE-47, BDE-99, BDE-100, BDE-153, BDE-154, BDE-183, and BDE-209.

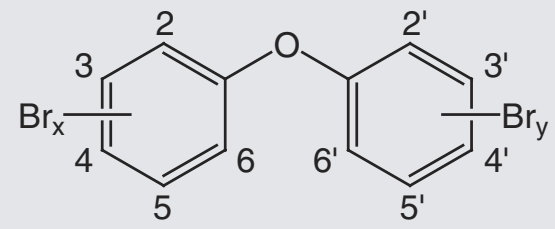

Congeners

BDE-28

BDE-47

BDE-99

BDE-153

BDE-154

BDE-183

BDE-209
Polybrominated diphenyl ethers (PBDE)

2,4,4'-Tribromodiphenyl ether 2,2',4,4'-Tetrabromodiphenyl ether $2,2^{\prime}, 4,4$ ',5-Pentabromodiphenyl ether $2,2^{\prime}, 4,4^{\prime}, 5,5^{\prime}$-Hexabromodiphenyl ether $2,2^{\prime}, 4,4^{\prime}, 5,6^{\prime}$-Hexabromodiphenyl ether 2,2',3,4,4',5',6-Heptabromodiphenyl ether Decabromodiphenyl ether 
trophic level [48]. Based on these data, correlations between PBDE levels in fish and the properties of the respective lakes were explored. In order to assess human exposure through farmed fish as well, rainbow trout (Oncorhynchus mykiss) from four Swiss fish farms were analyzed, and daily PBDE intake through human consumption of farmed fish was also estimated.

\section{PBDE in Whitefish}

\section{From Swiss Lakes}

Whitefish (Coregonus sp.) from eight different Swiss lakes (Lake Geneva, Lake Greifen, Lake Biel, Lake Lucerne, Lake Zürich, Lake Neuchâtel, Lake Constance, and Lake Thun), collected by the fishery and hunt authorities were selected for analysis. PBDE were detected in all whitefish samples. Lipid contents of the pooled samples ranged from 1.9 to $6.8 \%$. PBDE levels in lipids expressed as the sum of BDE-28, BDE-47, BDE-99, BDE-100, BDE-153, BDE-154, and BDE-183 were between 36-165 ng/g lw, corresponding to a wet weight (ww) concentration of 1.6-7.4 $\mathrm{ng} / \mathrm{g}$ ww. The highest PBDE concentrations in our study were found in whitefish from Lake Greifen (165 ng/g lw), and the lowest concentrations were detected in whitefish from Lake Thun (36 ng/g lw). Near known and suspected point sources, PBDE levels up to $27^{\prime} 000 \mathrm{ng} / \mathrm{g}$ lw [49] were measured. The congener pattern is similar for all whitefish samples, a typical pattern is shown in Fig. 3a. The pattern is dominated by BDE-47, followed by BDE-99 and BDE-100. Congeners BDE-153 and BDE154 are found in similar concentrations, just below the levels of BDE-100. BDE-183 could be detected in trace amounts, only. This pattern is related to the congener pattern of a typical commercial PeBDE product, such as Bromkal 70-5DE (Fig. 3b). However, the ratio of BDE-47 to BDE-99 detected in the whitefish samples is about 2 , while Bromkal 70-5DE shows a ratio of about one for these two congeners.

\section{PBDE in Farmed Rainbow Trout}

Farmed rainbow trout (Oncorhynchus mykiss) from four different Swiss fish farms were selected for analysis. PBDE were detected in all rainbow trout samples. PBDE levels in lipids expressed as the sum of BDE-28, BDE-47, BDE-99, BDE-100, BDE-153, BDE-154, and BDE-183 between $12-24 \mathrm{ng} / \mathrm{g}$ lw $(0.74-1.3 \mathrm{ng} / \mathrm{g}$ ww) were found. Lipid contents of the pooled samples ranged from 4.1 to $7.3 \%$. Compared to the levels measured in wild whitefish (36-165 ng/g lw, 1.6-7.4 ng/g ww), concentrations of PBDE in farmed rainbow trout were significantly lower. The PBDE congener pattern is similar for all samples, a typical pattern is shown in Fig. 3c. The pattern is dominated by BDE-47, followed by BDE-99 and BDE-100. Congeners BDE-153 and BDE-154 are found in similar concentrations, clearly below the level of BDE-100. BDE- 183 could be detected in trace amounts only. Compared to the PBDE congener pattern for wild whitefish, the ratio BDE-47 to BDE-99 is significantly higher. The low relative concentration of BDE-99 found for the farmed rainbow trout samples compared to the wild whitefish samples might be due to factors such as feed (commercial fish feed versus natural feed), species differences in PBDE uptake (rainbow trout versus whitefish) and differences in metabolism and trophic level.

\section{Atmospheric Deposition of PBDE}

All lakes investigated in our study are situated in populated areas, and none of them can be considered as a background site. Since total PBDE levels are low compared to sites near known point sources of PBDE, we assume that no major point source is present and that the PBDE content in our fish samples is mainly caused by dif-
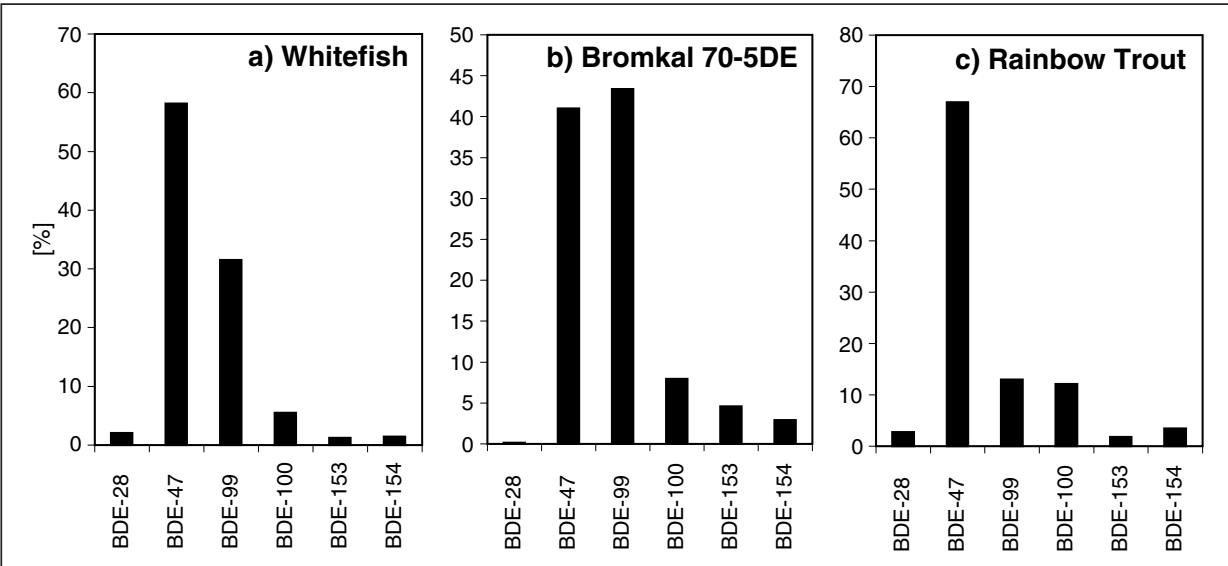

Fig. 3. Congener patterns (BDE-28, BDE-47, BDE-99, BDE-100, BDE-153, BDE-154, and BDE183) of whitefish (Lake Greifen) compared to Bromkal 70-5DE (flame retardant, commercial product) and rainbow trout (Swiss farmed fish). fuse contamination, such as atmospheric deposition. Without attempting a detailed analysis based on sediment, water column, and biota concentrations, correlation of PBDE levels in whitefish with lake parameters such as volume, surface, and number of inhabitants were investigated. If atmospheric deposition (assumed to be constant throughout Switzerland) is a major input pathway for PBDE, and under the assumption that elimination rates are similar for all lakes, high PBDE levels in fish from shallow lakes (i.e. high surface/volume ratio) would be expected. Fig. 4 shows that whitefish PBDE levels [ng/g lw] and surface/volume ratio $\left[\mathrm{km}^{-1}\right]$ of the respective lakes do indeed correlate $\left(\mathrm{r}^{2}=0.70\right)$, suggesting atmospheric deposition as an input pathway for PBDE. Compared to its surface/volume ratio, whitefish from Lake Lucerne showed considerably higher PBDE levels in whitefish than all other lakes which allows some speculation about the presence of local PBDE sources in this case. Additionally, the BDE-47 to BDE-99 ratio is also lower for the samples from Lake Lucerne compared to all other lakes (data not shown). A final conclusion on the presence of a local source, however, will need further investigation, since this data is based on a single composite sample (ten individuals). If Lake Lucerne is omitted from the data set, the correlation coefficient (whitefish PBDE levels versus surface/volume ratio) is close to one $\left(r^{2}=0.96\right)$. The correlation between the PBDE concentration and the ratio of human population (inhabitants in the catchment area) and lake volume, however, was less pronounced $\left(r^{2}=0.59\right)$, as were other correlations between PBDE concentrations and lake properties. Based on these data, wastewater effluents might represent only a minor source of PBDE input to the lakes investigated.

\section{Human Exposure of PBDE Through Fish Consumption}

In some parts of Switzerland (Lake Geneva region), up to $70 \%$ of the population eats fish 1-2 days a week [50]. Based on an average daily consumption of $20 \mathrm{~g}$ fish [51] from Lake Biel with a PBDE content of $7.4 \mathrm{ng} / \mathrm{g}$ ww (highest wet weight PBDE concentration detected in this study), a maximum daily intake of $0.15 \mu \mathrm{g}$ PBDE was estimated $(0.026 \mu \mathrm{g} /$ day for Swiss farmed trout). This number corresponds to the lower end of the estimate for the total PBDE intake of the Nordic consumer of $0.2-0.7 \mu \mathrm{g} /$ day reported by Darnerud and coworkers [38]. Based on the current knowledge on PBDE, they consider the lowest observed adverse effect level (LOAEL) of the PBDE group to be 1 


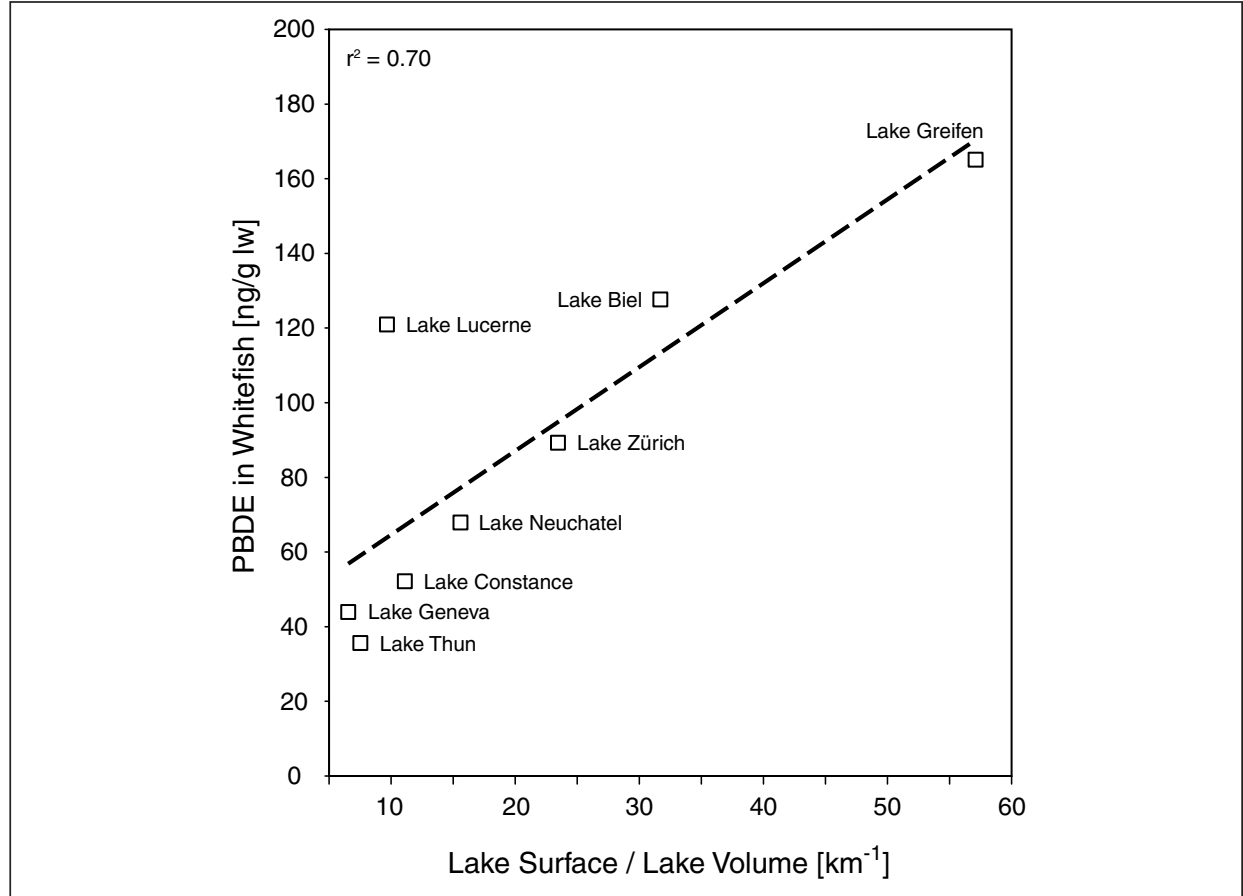

Fig. 4. Surface/volume $\left[\mathrm{km}^{-1}\right]$ ratio of each lake versus the PBDE levels $[\mathrm{ng} / \mathrm{g} \mathrm{Iw}]$ (sum of BDE-28, BDE-47, BDE-99, BDE-100, BDE-153, BDE-154, and BDE-183) in whitefish.

$\mu \mathrm{g} / \mathrm{kg} /$ day (preliminary value due to data gaps including carcinogenicity, reproduction and developmental toxicity as well as additional routes of exposure). In the light of continued use of PBDE in large quantities, monitoring levels of these compounds will continue to be an important issue.

Received: July 5, 2003

[1] R. Carson, 'Silent Spring', Houghton Mifflin Company, Boston, 1962.

2] N.V. Heeb, I.S. Dolezal, T. Bührer, P. Mattrel, M. Wolfensberger, Chemosphere 1995, 31, 3033.

[3] S. Wunderli, M. Zennegg, I.S. Dolezal, D. Noger, P. Hasler, Organohalogen Compounds 1996, 27, 231.

[4] S. Wunderli, M. Zennegg, I.S. Dolezal, E. Gujer, U. Moser, M. Wolfensberger, P. Hasler, D. Noger, C. Studer, G. Karlaganis, Chemosphere 2000, 40, 641

[5] A. Mayer, N.V. Heeb, J. Czerwinski, M. Wyser, SAE 2003, 2003-01-0291.

[6] P. Schmid, E. Gujer, S. Degen, M. Zennegg, A. Kuchen, C. Wüthrich, J. Agric. Food Chem. 2002, 50, 7482

[7] M. Kohler, M. Zennegg, R. Waeber, Environ. Sci. Technol. 2002, 36, 4735.

[8] M. Kohler, T. Künniger, P. Schmid, E. Gujer, R. Crockett, M. Wolfensberger, Environ. Sci. Technol. 2000, 34, 4766

[9] M. Kohler, T. Künniger, Holz Roh Werkst. 2003, 61, 117.

[10] N.V. Heeb, A.-M. Forss, C. Bach, Atmos. Environ. 1999, 33, 205.

[11] N.V. Heeb, A.-M. Forss, C. Bach, P. Mattrel, Atmos. Environ. 2000, 34, 1123.

[12] N.V. Heeb, A.-M. Forss, C. Bach, S. Reimann, A. Herzog, H.W. Jäckle, Atmos. Environ. 2000, 34, 3103.
[13] N.V. Heeb, A.-M. Forss, C. Bach, T. Schweizer, Int. J. Vehicle Design 2001, 27, 296.

[14] N.V. Heeb, A.-M. Forss, M. Weilenmann, Atmos. Environ. 2002, 36, 4745.

[15] N.V. Heeb, A.-M. Forss, C. Saxer, P. Wilhelm, Atmos. Environ. 2003, in press.

[16] N.V. Heeb, C. Bach, P. Mattrel, A. Paul, H. Vonmont, M. Wolfensberger, N. Kläntschi, Chimia 1997, 51, 741.

[17] J. Staehelin, C. Keller, W. Stahel, K. Schläpfer, S. Wunderli, Atmos. Environ. 1998, 32, 999

[18] A.C. Gerecke, M. Kohler, M. Zennegg, P. Schmid, N.V. Heeb, Organohalogen Compounds 2003, 61, 155-158.

[19] M. Kohler, M. Zennegg, A.C. Gerecke, P. Schmid, N. Heeb, Organohalogen Compounds 2003, 61 .

[20] M. Kohler, N.V. Heeb, Anal. Chem. 2003, 75, 3115-3121.

[21] P. Schmid, E. Gujer, M. Zennegg, C. Studer, Chemosphere 2003, 53, 129-136.

[22] M.S. McLachlan, H. Thoma, M. Reissinger, O. Hutzinger, Chemosphere 1990, 20, 1013.

[23] W. Slob, J.A. van Jaarsveld, Chemosphere 1993, 27, 509

[24] P. Fürst, G.H.M. Krause, D. Hein, T. Delschen, K. Wilmers, Chemosphere 1993, 27, 1349.

[25] F. Schuler, P. Schmid, C. Schlatter, Chemosphere 1997, 34, 711 .

[26] R. Malisch, Organohalogen Compounds 1998, 38, 65 .

[27] C. Rappe, M. Nygren, G. Lindström, H.R. Buser, O. Blaser, C. Wüthrich, Environ. Sci. Technol. 1987, 21, 964.

[28] P. Schmid, C. Schlatter, Chemosphere 1992, 24, 1013.

[29] European Commission Health \& Consumer Protection Directorate-General, 'Assessment of dietary intake of dioxins and related PCBs by the population of EU Member States', European Union, Brussel, 2000, p. 115

[30] WHO, 'Assessment of the health risk of dioxins: re-evaluation of the Tolerable Daily Intake (TDI)', WHO European Centre for Environment and Health, International Programme on Chemical Safety, Geneva, 1998, p. 28.

[31] Swiss Agency for the Environment Forests and Landscape, 'Dioxine und Furane - Standortbestimmung, Beurteilungsgrundlagen, Massnahmen', Swiss Agency for the Environment Forests and Landscape, Berne, 1997, p. 128.

[32] U. Quass, M. Fermann, G. Bröker, Chemosphere 2003, in press.

[33] P. Fürst, Lebensmittelchemie 1999, 53, 79.

[34] P. Fürst, K. Wilmers, Organohalogen Compounds 1999, 43, 325.

[35] R.E. Alcock, K.C. Jones, Environ. Sci. Technol. 1996, 30, 3133.

[36] M. Zennegg, M. Kohler, A.C. Gerecke, P. Schmid, Chemosphere 2002, 51, 545.

[37] K.S. Betts, Environ. Sci. Technol. 2002, 36, 188A.

[38] P.O. Darnerud, G.S. Eriksen, T. Johannesson, P.B. Larsen, M. Viluksela, Environ. Health Perspect. 2001, 109, 49

[39] A.H. Tullo, Chem. Eng. News 2000, 78

[40] R. Renner, Environ. Sci. Technol. 2000, 34, 452A.

[41] C.A. de Wit, Chemosphere 2002, 46, 583.

[42] J. de Boer, P.G. Wester, H.J. Klamer, W.E. Lewis, J.P. Boon, Nature 1998, 394, 28

[43] K.S. Betts, Environ. Sci. Technol. 2002, $36,50 \mathrm{~A}$.

[44] K. Norén, D. Meironyté, Chemosphere 2000, 40, 1111.

[45] J. de Boer, K. de Boer, J.P. Boon, 'Polybrominated Biphenyls and Diphenyl Ethers', in 'The Handbook of Environmental Chemistry', Ed. J. Paasivirta, Springer, New York, 1999.

[46] I.A. Meerts, J.J. van Zanden, E.A. Luijks, I. van Leeuwen-Bol, G. Marsh, E. Jakobsson, A. Bergman, A. Brouwer, Toxicol. Sci. 2000, 56, 95 .

[47] N. Riccardi, J. Limnol. 2000, 59, 179.

[48] M.J. Vander Zanden, B.J. Shuter, N. Lester, J.B. Rasmussen, Am. Nat. 1999, 154, 406.

[49] Ö. Andersson, G. Blomkvist, Chemosphere 1981, 10, 1051.

[50] BFS, 'Schweizerische Gesundheitsbefragung 1997', Swiss Federal Statistical Office (BFS), Neuchâtel, 1998.

[51] R. Grüter, I. Schmid, R. Sieber, 'Verbrauch an Lebensmitteln in der Schweiz in den Jahren 1994/95', in 'Vierter Schweizerischer Ernährungsbericht', Ed. U. Keller et al., EDMZ, Bern, 1998. 